\title{
Empowering First Aiders Through Innovative Instructor Resources
}

\author{
J. Victoria Logan \\ Dominique MacDonald
}

\section{Purpose}

Instructors work to empower students with a 'willingness to act' (Canadian Red Cross Society, 2017), however Zee \& Koomen (2016) identified that, in general, instructor fatigue was associated with reduced outcomes for students. With these two thoughts in mind, we aimed to help instructors by providing valuable, fun and fresh resources and experiences to help decrease their fatigue and empower participants.

\section{Description of activity}

To address instructor fatigue at the University of Calgary we implemented first aid instructor events twice a year.

The first of the two events is a first aid instructor training day. Here, our staff instructors teach a free first aid recertification for University of Calgary employees. The day has two valuable components. First, while instructors teach the recertification they are observed by their supervisor and then given feedback on their teaching. Second, while their peers are teaching, the rest of the instructors spend time planning and preparing new teaching tools that the entire instructor team will have access to.

The second University of Calgary event is the Annual UCalgary Lifeguard Games. First Aid instructor's role in this day involves judging a first aid competition. Instructors get to see firsthand what knowledge gaps still exist for first aiders.

\section{Implications}

The implication of our training day is two-fold. First, the day provides instructors with new activities and techniques to keep their teaching fresh. Second, they receive feedback from their supervisor that gives them the chance to further self-reflect and refine their teaching. Attendance at the Lifeguard Games, allows instructors to adjust future teaching to account for noted learning gaps.

Since beginning these two initiatives, Instructors have stated that they have increased their passion for teaching along with the amount of engaging activities they use.

\section{Engagement at conference}

At the conference, session participants were first given an overview of the two events hosted at the University of Calgary. Participants then got a chance to try out some of the activities created by our instructors. One 
activity used small items (pieces of foam, leather and tinfoil) to mimic wounds. These made hands-on checks more realistic and fun. Session attendees also played a memory matching game where players flipped over cards and aimed to pair a signs and symptoms card with a matching treatment card.

Participant engagement at the session and verbal feedback afterwards indicated that many instructors are eager for new games and activities to use in their practice.

\section{References}

Zee, M., \& Koomen, H. M. (2016). Teacher self-efficacy and its effects on classroom processes, student academic adjustment, and teacher well-being: A synthesis of 40 years of research. Review of Educational research, 86(4), 981-1015.

Canadian Red Cross Society. (2017). Comprehensive Guide for First Aid \& CPR. Retrieved from http://www.redcross.ca/crc/documents/comprehensive_guide_for_firstaidcpr_en.pdf 
Conference Abstract

International First Aid Education Conference, 22-25 April 2018 